\title{
La crítica de Plotino a la concepción aristotélica del tiempo en En. III 7
}

\author{
Review of Plotinus to the aristotelian concept of time \\ in En. III 7
}

\author{
Fernando G. Martin de Blassi \\ Universidad Nacional de Cuyo-CONICET (Argentina) \\ martindeblassi@hotmail.com
}

Recibido: 16/07/2014

Aceptado: 06/12/2014

\section{Resumen}

El presente trabajo intenta mostrar de qué manera Plotino refuta la noción aristotélica del tiempo como «número»o «medida del movimiento», cuáles son las aporías que plantea, cómo las compulsa con sus propios argumentos y qué soluciones propone con respecto a esa misma confrontación. Todo esto será encauzado a partir de un estudio descriptivo y analítico, acompañado de una lectura a la vez hermenéutica y crítica de los textos seleccionados para esta ocasión.

Palabras clave: Alma, Aristóteles, Movimiento, Plotino, Tiempo.

\begin{abstract}
This work will study how Plotinus rejects the Aristotelian notion of time as a «number» or «measure of movement», what are the paradoxes which the Neoplatonic poses, how he compares them to their own arguments and what solutions he proposes about this dispute. It will use a descriptive and analytical methodology, accompanied by critical and hermeneutic reading of texts selected for this occasion.

Keywords: Aristotle, Movement, Plotinus, Soul, Time.
\end{abstract}




\section{Sumario}

1. Consideraciones preliminares

2. Sinopsis estructural de En. III 7

3. Deslinde conceptual del tiempo en En. III 7

4. Plan exegético y crítico sobre las opiniones precedentes en torno al tiempo

4. 1. El tiempo no se da sin movimiento

5. ¿Cabe al tiempo ser número o medida del movimiento?

5. 1. El tiempo no es la medida de todo movimiento $(9,1-12)$

5. 2. El tiempo no es ni un número abstracto ni magnitud continua $(9,12-24)$

5. 3. El tiempo no es ni movimiento mensurado ni sujeto mensurador $(9,24-$ 84)

6. A modo de conclusión: Aristóteles confunde el metro con lo medido (13, 1-18)

7. Bibliografía

\section{Consideraciones preliminares}

El tratado de Plotino correspondiente a En. III $7,{ }^{1}$ sobre el tema de la eternidad y el tiempo, pertenece a las lecciones del ciclo escolar de 267-268, es el número cuadragésimo quinto en la cronología de su producción literaria y cierra el segundo período de su vida. ${ }^{2}$ El escrito de marras es introducido por un breve exordio donde su autor determina el orden que seguirá a lo largo del estudio en cuestión. Se divide luego en dos grandes apartados teóricos: uno dedicado al examen de la eternidad y otro al del tiempo. Cada uno de ellos está organizado, asimismo, a partir de una indagación crítica sobre las aporías que comportan ciertas afirmaciones precedentes en materia de eternidad o de tiempo. Allí son expuestas, a la vez que enjuiciadas, las opiniones más autorizadas de los antiguos filósofos en relación con tal asunto. A continuación de este procedimiento dialéctico, el curso de la discusión se orienta a que Plotino explique su propia comprensión acerca de la eternidad y el tiempo en vista de las exigencias de su mismo sistema.

\footnotetext{
${ }^{1}$ Entre los aportes bibliográficos se cuenta con la ed. bilingüe (griego-alemán) del presente tratado preparada por BeIERWALtes, Werner. Über Ewigkeit und Zeit (Enn. III 7). Texto gr., trad. al. y com. Frankfurt am Main: Klosterman, 1967 (1981³), y con la traducción anotada de PigLeR, Agnès. Ennéade III, 7 [45]: De l'éternité et du temps. Plotin. Paris: Ellipses, 1999. Para la referencias y citas he tenido a la vista tanto la edición crítica del texto griego preparada por Henry, P. and H.-R. Schwyzer, H.-R. Plotini opera, vol. 1. Leiden: Brill, 1951; cuanto la versión castellana Plotino. Enéadas III-IV. Intr., trad. y notas de J. IGaL. Madrid: Gredos, 1985. Retomo y desarrollo algunas ideas ya expuestas a modo de ponencia en el marco de las V Jornadas de Filosofía Patrística y Medieval, que se celebraron en la UNRosario del 16 al 18 de octubre de 2014.

${ }^{2}$ Cfr. Porfirio. Vida de Plotino. Intr., trad. y notas de IGAL, J. Madrid: Gredos, 1982, 5, 57.
} 
La obra mencionada ha tenido una gran influencia dentro de la historia de la filosofía por su pervivencia en el pensamiento de otros autores como es el caso de Agustín de Hipona. ${ }^{3}$ E. Albizu ha representado el esquema temporal plotiniano por medio de la metáfora de la fuente, para el cual hay un punto originario funcional e inmutable: ahora, instante o presente, del que brota una corriente dirigida hacia atrás, hacia el pasado, y otra dirigida hacia adelante, hacia el futuro. La imagen arquetípica del esquema de la fuente es la del emanar de una concentración primera; su nítida formulación - advierte Albizu - se halla en Plotino pues tiempo es el progresivo diluirse ( $\dot{\varepsilon} v \mu \varepsilon \tau \alpha \beta o \lambda \alpha \tilde{\varsigma} \varsigma$

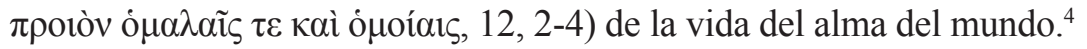

En el marco de una edición de hace pocos años que contiene textos seleccionados de las En., traducidos al español y anotados, se dice que el tratado en cuestión es uno de los escritos plotinianos más accesibles, cuya lectura presupone relativamente poco conocimiento de los detalles de su sistema y de los antecedentes históricos inmediatos. La investigación dialéctica de Plotino acerca del tiempo es una crítica brillante de las concepciones de filósofos anteriores, en especial de Aristóteles, mientras que su concepto de tiempo es de gran importancia para la comprensión del tratamiento que hace a propósito del Alma y del mundo sensible. ${ }^{5}$ Por su parte, la investigación acerca del tiempo desarrollada en Phys. IV 10-14 ha sido valorada como una pieza clave dentro de la filosofía natural que presenta el Estagirita, en la medida en que configura un texto clásico dentro de la historia general del amor a la sabiduría, cuya importancia difícilmente podría ser exagerada. ${ }^{6}$

Por lo que concierne al presente trabajo, es importante señalar que su objetivo principal consiste en mostrar de qué manera Plotino refuta la noción aristotélica del tiempo, cuáles son las aporías que indica, cómo las compulsa con sus propios argumentos y qué soluciones propone con respecto a esa misma confrontación. En aras de esta propuesta, me detendré en el abordaje de En. III 7, 8-10, donde el Neoplatónico examina con detenimiento las opiniones filosóficas anteriores a él, en cuyo seno ha cristalizado un conocimiento acerca del tiempo. Como parte integrante de esa tradición, se halla la clásica definición aristotélica del tiempo en cuanto «número del

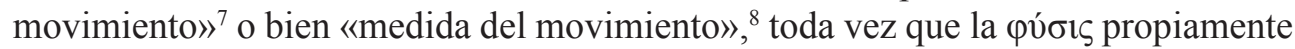

\footnotetext{
${ }^{3}$ Cfr. Guitton, Jean. Le temps et l'éternité chez Plotin et Saint Augustin. Paris: Boivin et C ${ }^{\text {ie }}$. Éditeurs, 1933.

${ }^{4}$ Cfr. Albizu, Edgardo. «Esquemas de tiempo». Letras, 48, 84-85, 1976, 27-28.

${ }^{5}$ Cfr. Plotino. Enéadas. Textos esenciales. Intr., trad. y notas de Santa Cruz, Ma. I.-Crespo, Ma. I. Buenos Aires: Colihue, 2007, 190, n. 654.

${ }^{6}$ Cfr. Aristóteles. Física. Libros III-IV. Trad., intr. y com. de Vigo, A. Buenos Aires: Editorial Biblos, 1995, 232-233, ad 217b 29.

${ }^{7}$ Phys. 219b 2.

${ }^{8}$ Phys. 220b 32-221a 1. Para una síntesis de la doctrina del tiempo en la física aristotélica cfr. Ross, William David. Aristotle's Physics. Revised text, intr. and comm. Oxford: Clarendon Press, 1936, 6369.
} 
dicha es «la ov̉oía de aquellas cosas que tienen el principio del movimiento en sí mismas en cuanto tales». ${ }^{9}$

Antes de ingresar in medias res, me parece oportuno establecer algunas previsiones de orden metodológico. La presente investigación no tiene el propósito fundamental - que sería, por lo demás, sencillamente fatuo - de dirimir cuál de ambos pensadores, si Aristóteles o Plotino, tiene razón en su doctrina acerca del tiempo. Esta pretensión conduce de modo fatal a trompicar en indefinidas contradicciones, toda vez que reclama la determinación previa - y consecuente justificación - de ciertos parámetros o criterios interpretativos sobre cuya base pueda establecerse una valoración en términos de aceptación o rechazo de lo dicho por cada autor. A este grupo de observaciones podría oponérsele otro tanto, con igual derecho y mejor fundamento, y así sucesivamente ad infinitum. Antes de abrir juicio sobre la verdad o falsedad de cada posición, estimo que lo menos arriesgado pero más eficaz en orden a la comprensión de la temática desglosada es ajustarse, con la mayor fidelidad posible, al dato doctrinal tal como se ofrece en los documentos seleccionados para esta ocasión. Cada una de tales posiciones es ponderable dentro del horizonte de su misma filosofía y de acuerdo con los principios a que los enfrenta su propio pensamiento. Con esto ya se tiene un marco de análisis lo suficientemente complejo que contribuye a la realización posterior de una investigación histórica y crítica mejor fundada y dispone, a su vez, de horizontes más amplios para interpretar los textos en relación con los hechos. Es necesario aclarar asimismo que, ante los límites a que obliga un trabajo de semejante tenor, he decidido encauzar este estudio desde el enfoque plotiniano de la cuestión, recuperando su propia teoría sobre el tiempo y procurando iluminar, desde esa misma comprensión, la crítica dirigida contra Aristóteles. Esto quiere decir que, en las páginas siguientes, los aportes del Estagirita sobre el tema del tiempo no han sido considerados como un tópico central del presente artículo sino, antes bien, como elementos útiles para dilucidar mejor el juicio formulado por Plotino.

\section{Sinopsis estructural de En. III 7}

Comienza Plotino admitiendo la opinión, por lo demás generalizada en el común de la gente, de que cuando uno habla de la eternidad ( $\tau$ òv aĩov $\alpha, 1,1)$ o del

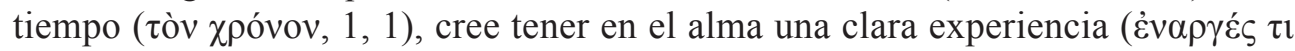

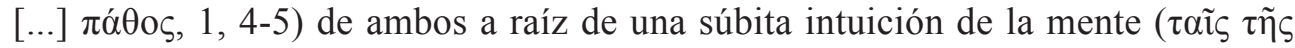

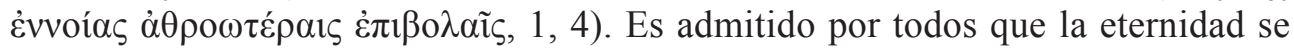

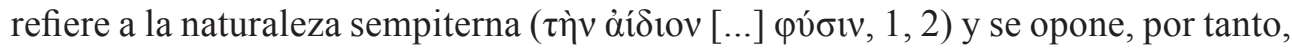
al tiempo ya que por medio de este es designado el universo y lo que deviene ( $\tau$ ò

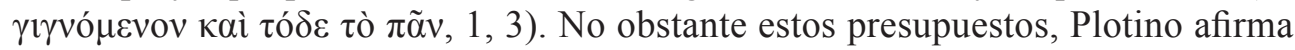

\footnotetext{
${ }^{9}$ Met. 1015a 13-15. Sigo la versión de la ed. trilingüe preparada por García YeBra, Valentín. Metafisica de Aristóteles. Madrid: Gredos, 1998.
} 
que cuando se quiere saber de manera fundada en qué consiste cada una de tales

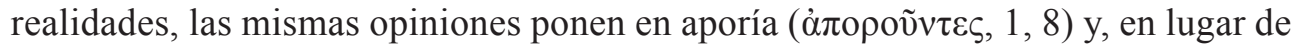
contribuir al conocimiento preciso de ellas, terminan por obstaculizarlo. Explicita el autor que, para sortear las mismas dificultades a las que nos conducen nuestras propias opiniones, conviene acudir a las afirmaciones de los antiguos pensadores avezados en tales cuestiones, diversas unas de otras, aunque posiblemente se trate de las mismas afirmaciones pero dichas, en cada caso, de forma diferente. Hay que detenerse en tales posiciones, pues cabe la posibilidad de pensar que algunos de los filósofos precedentes hayan descubierto la verdad en relación con el examen de la eternidad y del tiempo. Si bien - como él mismo aclara - no se trata de admitir indiscriminadamente cualquiera de las opiniones al respecto, puesto que algunos han acertado en mayor grado (oi $\tau 0 \chi o ́ v \tau \varepsilon \varsigma \mu \alpha ́ \lambda 1 \sigma \tau \alpha, 1,14-15$ ). Por tanto, ante el hecho de que también uno pueda llegar a comprender con asidero las cuestiones correspondientes al tiempo y la eternidad, deben examinarse las posiciones más autorizadas de los sabios.

En este sentido, el método exegético seguido por Plotino parte del análisis de las doctrinas de los predecesores en relación con la eternidad y el tiempo, pero no aceptándolas de manera indiscriminada sin haber establecido antes una valoración a propósito de su justeza doctrinal. En el proceder reflexivo de Plotino, la aceptación de una teoría filosófica implica que tal cúmulo de afirmaciones reúne dos condiciones necesarias: (1) es consistente con los textos de los filósofos más reputados sobre el asunto en cuestión y (2) está de acuerdo con las propias concepciones comunes sobre el tema. ${ }^{10}$ Es en virtud de la seriedad misma propia de toda actividad intelectual que, para satisfacer el segundo requisito y asegurar la certeza de tales concepciones, Plotino insiste en someterlas a un riguroso análisis a los efectos de depurar su contenido de confusiones y presuntos engaños. Plantea que en primer lugar será necesario preguntarse sobre la eternidad ( $\pi \varepsilon \rho i ̀ ~ \tau o \tilde{~} \alpha i \tilde{\omega} \nu o \varsigma$, 1,17): qué piensan los que sostienen que ella es algo diferente del tiempo. Si se conociere, por cierto, lo estable a modo de modelo ( $\tau$ ò $\pi \alpha \rho \alpha ́ \delta \varepsilon 1 \gamma \mu \alpha, 1,19)$, podrá

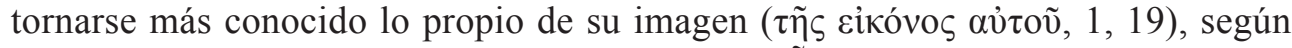

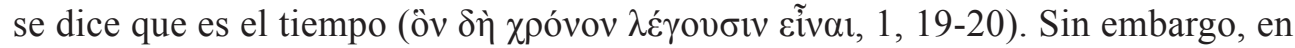
opinión del mismo autor, también existe la posibilidad de que alguien, imaginando

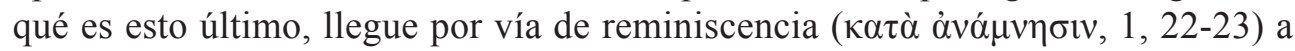
la contemplación de la eternidad y pueda, finalmente, dar cuenta de ella como el modelo al cual el tiempo se asemeja.

La estructura literaria del tratado en cuestión comprende una disposición clara y simétrica con respecto a su forma: la primera parte aborda el tema de la eternidad, mientras que la segunda el del tiempo. Tal conformación refleja, empero, otra estructura mucho más importante - igualmente simétrica, aunque jerárquica - que la pre-

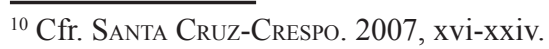


cede y justifica como tal: el tiempo, vida del Alma, es imagen de la eternidad, vida del Intelecto. Esta comprensión de la relación entre eternidad y tiempo fundamenta en primera instancia por qué motivo Plotino comienza su estudio interrogándose por la naturaleza de la eternidad, para luego desarrollar la investigación correspondiente al tiempo. ${ }^{11}$

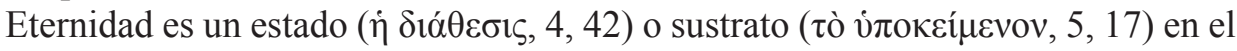
que se halla la sustancia cabal y entera del Intelecto, atributo que dimana del ser inteligible y subsiste conjuntamente con él. ${ }^{12} \mathrm{El}$ tiempo, por su parte, no debe concebirse fuera del Alma ( $\left.{ }^{\xi} \xi \omega \theta \varepsilon v \tau \tilde{\eta} \varsigma \psi v \chi \tilde{\eta} \varsigma, 11,59\right)$, ni como un acompañamiento, ni como

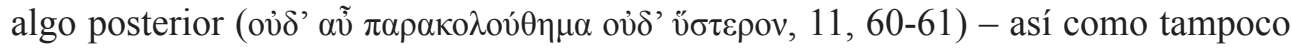
debe comprenderse la eternidad fuera del ser inteligible - sino como algo que se ve

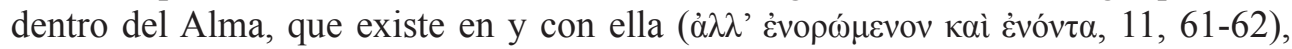
como la eternidad con respecto al Intelecto. Ahora bien, si el universo sensible del devenir como un todo es una imagen del universo inteligible del ser donde residen las formas o arquetipos siempre-existentes, la relación presente entre tiempo y devenir sensible será la misma que se da entre eternidad y ser inteligible. De esto se sigue que tanto la eternidad cuanto el tiempo son realidades análogas y ello implica que los atributos de aquella tendrán una vinculación igualmente análoga con los de este en el sentido de que la imagen guarda cierta relación con su arquetipo, aun cuando esté presente en un plano inferior y dependiente de él. Siendo el tiempo una imagen de la eternidad, se requiere analizar primero su ejemplar para luego elucidar lo que de él procede. Tal estudio ocupa los cp. 2-6 del tratado plotiniano. Una vez que su autor determina el concepto de eternidad y lo que le es inherente en cuanto tal, pasa a la indagación sobre el tiempo que abarca los cp. 7-13 de su escrito. ${ }^{13}$

Por lo que al tiempo respecta, el punto de partida de la exposición plotiniana es la exégesis del pasaje correspondiente al Timeo de Platón (37d-e), donde se lo caracteriza como imagen móvil de la eternidad. Dice Platón:

«Entonces, como éste [el progenitor o demiurgo] es un ser viviente eterno, intentó que este mundo lo fuera también en lo posible. Pero dado que la naturaleza del mundo ideal es sempiterna y esta cualidad no se le puede otorgar completamente

\footnotetext{
${ }^{11}$ Cfr. Igal. 1985, 191-196.

${ }^{12} \mathrm{Cfr}$. además 11,2 .

${ }^{13}$ En el apartado de En. III 7, 13, 41-69, Plotino cierra su tratado con la enumeración de tres problemas que se siguen del estudio realizado y cuya consideración queda pendiente para una ulterior investigación. Ellos son: (a) el movimiento del universo depende del movimiento del Alma; si bien este no depende ya de un movimiento anterior, porque lo anterior es la eternidad (13,41-47); (b) el tiempo está en todas partes porque el movimiento del Alma, que es el primario, está en todas partes (13, 47-53); (c) en el hombre, el movimiento externo de los miembros depende de un movimiento interior, y éste, del movimiento del alma, pero el del alma no depende ya de un movimiento anterior; lo mismo se aplica al Alma del cosmos (13, 53-66).
} 
a lo generado, procuró realizar una cierta imagen móvil de la eternidad [Eỉì $\delta$ '

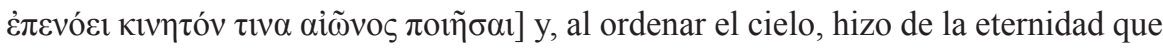
permanece siempre en un punto una imagen eterna que marchaba según el número, eso que llamamos tiempo». ${ }^{14}$

Plotino asume esta formulación, aunque la interpretará en relación con su propia doctrina al identificar el tiempo con la vida misma del Alma. ¿A qué se refiere, entonces, Plotino cuando habla del tiempo como extensión de la vida de la III Hipóstasis y por qué razón el concepto de «imagen móvil de la eternidad», de cuño platónico, sufre una reformulación con respecto a su contenido? Aun cuando esta pregunta demande por sí sola un estudio aparte, ${ }^{15}$ es conveniente, cuando no necesario, mostrar de una manera sintética pero esclarecedora cuál es el núcleo teórico sobre cuya base Plotino está comprendiendo lo que es el tiempo mismo. Esto permitirá no sólo entender el horizonte conceptual desde el cual elabora su doctrina, sino también sopesar la crítica que hace a la noción aristotélica del tiempo y los alcances que ello supone en el contexto de sus propios aportes a ese tema.

\section{Deslinde conceptual del tiempo en En. III 7}

Hay que regresar al modo de ser de la eternidad, un estado que se presenta bajo

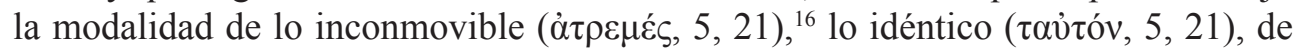

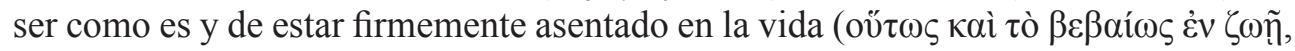
5, 21-22). Si se objetara que la sustancia inteligible está integrada por una multiplicidad, esto mismo no sería óbice para que a ella le competa por sí el predicado de eternidad, pues las formas que coexisten en el Intelecto son una multiplicidad por su

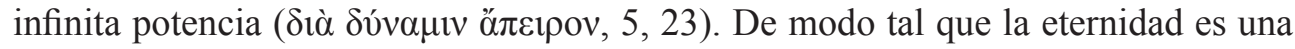

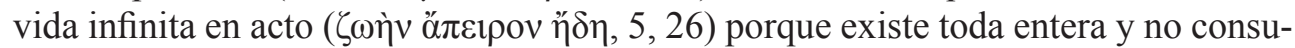
me nada de sí misma, por no haber dejado de existir ni estar a la espera de existir, so pena de no existir toda entera. Por consiguiente, el Intelecto es de índole bellísima y eterna ( $\pi \alpha \gamma \kappa \alpha ́ \lambda \eta \kappa \alpha i ̀ ~ \alpha ́ i ́ \delta ı \varsigma, 6,1)$, está en torno al Uno, procede de él y se encuentra

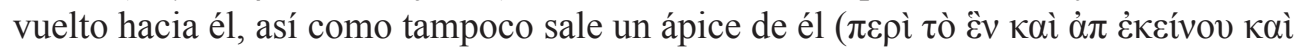

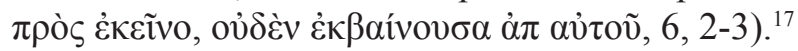

\footnotetext{
${ }^{14}$ Sigo la versión de Platón. Diálogos VI (Filebo, Timeo, Critias, Cartas). Intr., trad. y notas de Durán, Ma. A.; Lisi, F.; et al. Madrid: Gredos, 1982 (Reimpr. 2007).

${ }^{15} \mathrm{Cfr}$. mi «Algunas notas acerca de la comprensión plotiniana del tiempo: un sendero medieval en relación con el binomio permanencia-devenir». En: Díez, Ricardo (Comp.). Senderos medievales, pasos contemporáneos. IX Jornadas de Filosofia Medieval. Buenos Aires: Academia Nacional de Ciencias de Buenas Aires-Conicet, 2014 (Formato CD).

${ }^{16}$ Este término también es empleado por Parménides en Fragmenta 8, 4.

${ }^{17}$ De acuerdo con el planteo plotiniano, la eternidad no consiste en un mero transcurrir interminable de ahoras, ni mucho menos debe ser entendida como vida perdurable, pero inacabable, pues la noción de
} 
La naturaleza de lo eterno es algo total $(\pi \tilde{\alpha} v, 6,37)$ al par que existente (őv $, 6,37)$,

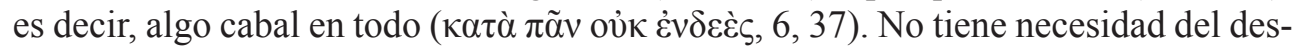
pués ( $\tau$ oṽ $\tilde{\varepsilon} \pi \varepsilon i \tau \alpha, 6,43)$ ni en orden a un nuevo tiempo finito $(\mu \varepsilon \mu \varepsilon \tau \rho \eta \mu \varepsilon ́ v o v, 6,44)$,

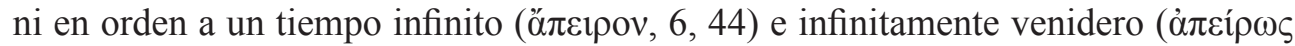
$\dot{\varepsilon} \sigma o ́ \mu \varepsilon v o v, 6,44-45)$. El Intelecto es tal que su ser no existe a partir del tiempo de una dimensión determinada, sino que es incluso anterior a toda dimensión. Como ni siquiera tiene dimensión, no le cuadra en absoluto entrar en contacto con alguna, su

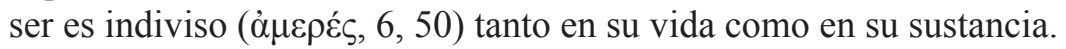

Esto afirma Plotino acerca de la eternidad: que es vida estable, en identidad y

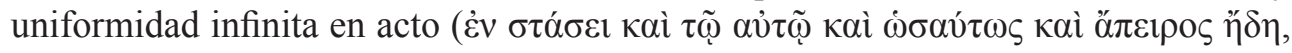
11, 45-46). El tiempo, por su parte, si es una imagen de la eternidad, habrá de ser, en lugar de la vida del todo inteligible, una vida distinta y como en sentido homónimo

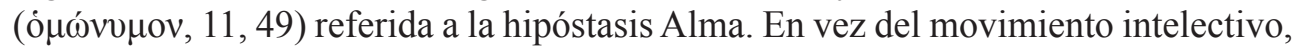

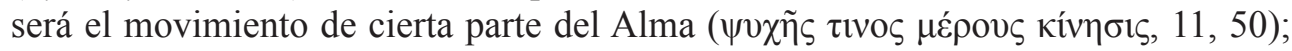
en vez de la identidad, uniformidad y permanencia, será lo que no permanece en

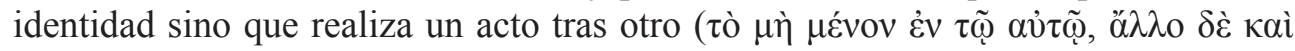
$\alpha \check{\alpha} \lambda \lambda_{0} \dot{\varepsilon} v \varepsilon \rho \gamma o \tilde{v} v, 11,52$ ); en vez de la no extensión y la unidad, una imagen suya: la de

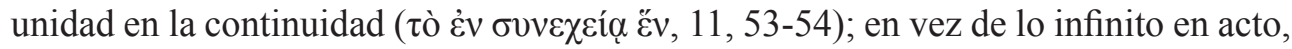
lo que se prolonga hasta el infinito en dirección a una interminable sucesión ( $\tau$ ò $\varepsilon i \zeta$

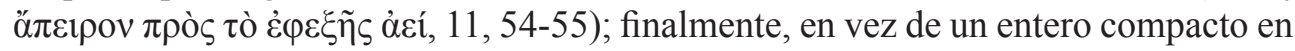

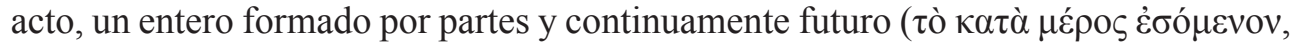
11,56). Así habrá de comportarse el tiempo en la medida en que imita perpetuamente el ser de lo eterno.

El tiempo no existía todavía, al menos no existía para los seres inteligibles que estaban en calma en sí mismos. Sin embargo, se puede generar el tiempo en teoría

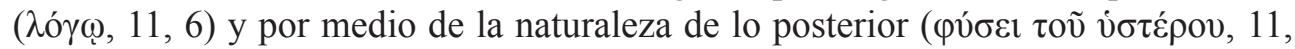
6). Según la concepción plotiniana, el tiempo no ha tenido comienzo ni tendrá fin, existe desde siempre y habrá de existir siempre por el hecho de ser cierta actividad

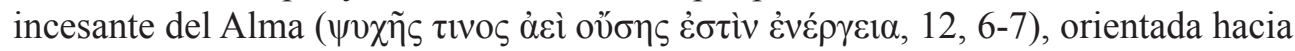

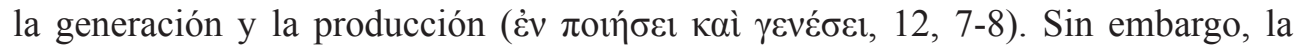
mente puede imaginar que el tiempo comienza o acaba en un momento dado para poder explicar su generación. Con todo, el tiempo es engendrado a continuación de los inteligibles, no en el tiempo, sino al interior de una procesión. Siguiendo a Pigler,

lo eterno no conlleva la sucesión del antes y el después. El Neoplatónico la identifica, por el contrario,

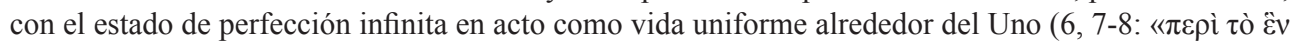

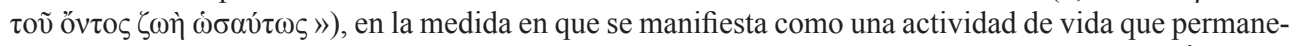

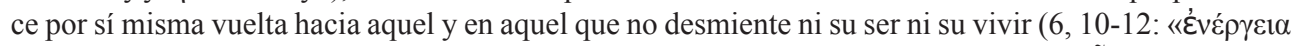

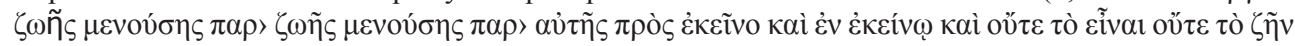

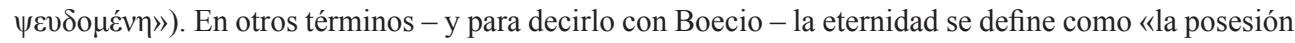
íntegra, a la vez que perfecta, de la vida sin término ni tasa [Interminabilis vitae tota simul et perfecta possessio]» (De Consolatione Philosophiae V 6, 10)]. 
dice Ma. I. Santa Cruz que el tiempo es un producto generado por el Alma universal en continuidad con la contemplación de las formas, lo cual permite caracterizar al tiempo arquetípico como el último eslabón inteligible que posibilita el paso de ese mundo al mundo sensible. En consonancia, por tanto, con estas proposiciones, es dable señalar que así como a la totalidad una y sempiterna no le corresponde en absoluto el hecho de haber comenzado a ser a partir de un cierto tiempo, así tampoco el cosmos ha sido pasible de comienzo temporal alguno, puesto que la anterioridad no le viene proporcionada en un sentido cronológico sino causal, a saber, por la causa del ser del universo siempre-existente. ${ }^{18}$

De esta manera, al decir que el Alma tiene una vida temporal, el predicado de «temporal» comporta un sentido bien diferente del que nombra la mera acepción cronológica del término. Pues, como potencia germinal de tiempo sucesivo, el Alma es principio de temporalidad, pero que se temporaliza a sí misma en su despliegue

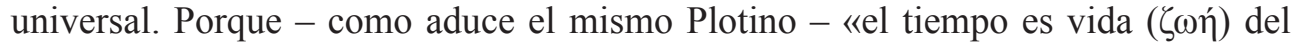
Alma en movimiento de transición de un modo de vida (ßíos) a otro» $(11,43-45)$. En relación con esta peculiar interpretación, que se vuelve ostensible a partir de la misma paráfrasis del texto plotiniano, F. García Bazán comenta que el Alma es tiempo en la medida en que, siéndolo implícitamente al desplegar su actividad productiva, se va temporalizando. Por eso, en rigor, ella es tiempo, mientras que el universo procedente desde siempre de ella está en el tiempo. De allí que el tiempo, considerado o bien en el Alma universal o bien en el universo generado por ella, sea respectivamente «imagen de la eternidad»o «imagen móvil de la eternidad». ${ }^{19}$ En este sentido, la noción estricta de tiempo es anterior a la sucesión consecutiva de lo anterior y posterior, modos que suponen la duración o cambios anímicos; es también anterior a la sucesión continua - ininterrumpida o interrumpida - del movimiento, asunto que conlleva a su vez la noción de espacio y, finalmente, es previa a la duración posible del reposo corporal y de su búsqueda interior. ${ }^{20}$

¿Bajo qué concepto, entonces, se ha manifestado el tiempo? Por medio de una cuasi personificación de él, Plotino narra su origen a través de un relato de raigambre mítica en el pasaje de 11, 11-20. Luego, en las líneas subsiguientes a ese passus, desarrolla una explicación, punto por punto, de tal relato. Permanecía el Alma en reposo consigo misma en el ser, con anterioridad a haber engendrado el antes y de haber sentido la necesidad de lo posterior. Había, empero, una cierta potencia inquieta de naturaleza afa-

\footnotetext{
${ }^{18}$ Cfr. Santa Cruz-Crespo. 2007, 196 y 198, nn. 678 y 685; Pigler. 1999, 50-51.

${ }^{19}$ Vale aclarar que esta determinación del tiempo no se contempla en el Timeo de Platón, quien solamente habla del tiempo como «imagen móvil de la eternidad» pero no lo piensa como vida germinal incipiente del Alma arquetípica. La distinción de marras manifiesta un desarrollo original por parte de Plotino, coherente, por lo demás, con los principios de su sistema filosófico.

${ }^{20}$ Cfr. García BAZÁN, Francisco. «El tiempo y la historia en el Neoplatonismo y San Agustín». Revista del Museo Mitre, 10, 1997, 74-77.
} 


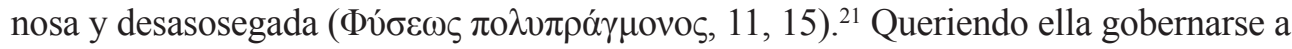
sí misma y ser ella misma, habiendo elegido a su vez buscar algo más que su estado presente, se puso en movimiento y, junto con ella, se puso en movimiento el tiempo. Dirigiéndose, entonces, hacia el después y lo no idéntico, sino distinto uno de otro, extendiendo esa marcha ( $\mu \tilde{\eta} \kappa о \zeta, 11,19)$, se ha forjado el tiempo como imagen de la

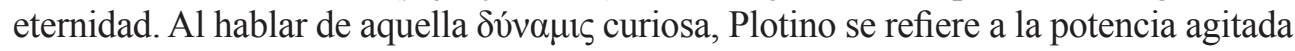
que pertenece a la sede inferior del Alma, potencia productora del tiempo y, en él, del mundo sensible. Así como una simiente que se desarrolla a partir de un germen inmóvil y avanza hacia la división y la multiplicidad en una pérdida progresiva de su unidad interna, así también actúa la parte inferior del Alma al constituir el mundo sensible. ${ }^{22}$ A propósito del movimiento de emanación y de la actividad que rige en el nivel de la tercera hipóstasis, A. H. Armstrong interpreta que el Alma contiene dos actividades: una inmanente y otra trascendente. La primera confiere existencia, vida y forma a los seres materiales; la otra anima el cosmos sensible sin intervenir en él. Porque se aplica al universo como ajena a él, el Alma es concebida como la suprema dirección, determinación, conformación y principio perpetuo a la vez que creativo. ${ }^{23}$

El mundo sensible entraña un movimiento que se asemeja al movimiento del Alma y que quiere ser una imagen de su ser, pues el Alma universal o arquetípica se halla en estado de contemplación respecto de la uniformidad eterna y perfecta del Intelecto. Sólo que ella no lo ve tal como lo inteligible es en sí mismo, sino como un espectáculo que acaece al interior de su ser. Esta ambigüedad de condición inteligible-intelectiva parece ser para Plotino lo más genuino de la tercera hipóstasis. Por ello, el Alma permanece siempre en el Intelecto como parte suya, aunque se expande en la generación del cosmos al que cuida como un cuerpo. Deseosa por actualizar la totalidad de lo visto por ella en el mundo eidético, es incapaz, no obstante, de apresarlo en su cabal integridad. Desde esta misma impotencia que implica el reflejo de lo intelectivo en ella y en su afán constante por conocer el todo, el Alma va desprendiendo los diversos aspectos que encierra ese paradigma inteligible. Se trata de una actividad sintética, pero compleja. Ella se pone a sí misma en el tiempo, al que produce en lugar de la eternidad. Haciendo esto, se temporaliza a sí misma ( $\pi \rho \tilde{\omega} \tau o v$

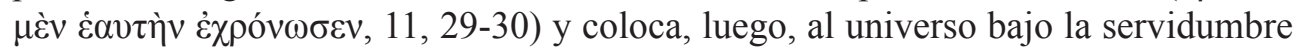

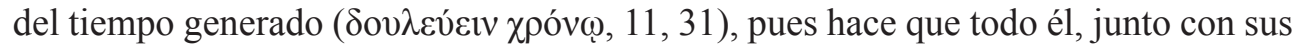
revoluciones, esté circunscripto a la sucesión temporal.

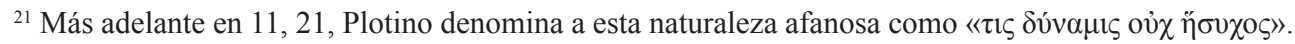

${ }^{22}$ En En. III 2, 2, 18-23, Plotino compara igualmente la producción del mundo sensible a partir de las

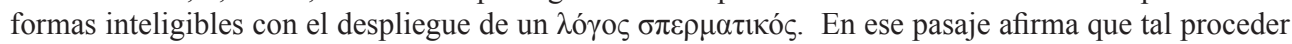
implica pérdida de perfección. El Neoplatónico caracteriza muchas veces la magnitud sensible como una imperfección frente al orden inextenso del mundo inteligible (Cfr. En. V 8, 1, 27-30; V 5, 11, 8-10; II 9, 17, 9-10).

${ }^{23}$ Cfr. Armstrong, Arthur Hilary. The Architecture of the Intelligible Universe in the Philosophy of Plotinus. Cambridge: University Press, 1940, 83 ss.
} 
Tal dinamismo resulta del movimiento propio de la procesión. Se colige, a partir de esto, que el tiempo no se aprehende fuera de la actividad misma del Alma que lo engendra toda vez que - como asevera Plotino - « [...] al desplegar sus actos uno tras otro, primero uno y luego, seguidamente, otro más, el Alma iba engendrando, junto con el acto, la sucesión consecutiva ( tiempo es dilatación de la intensidad de la vida anímica que acompaña al Alma como deseo o ansia de eternidad de su lado interior o cóncavo (principio temporalizante del cosmos), pero asimismo como condición de la sucesión y mutabilidad, de lo anterior y posterior en que se mueve el cosmos viviente, propio de su lado exterior o convexo. ${ }^{24}$

Si se diera por supuesto que el Alma ya no actúa, sino que su actividad ha cesado y que la porción desasosegada del Alma se ha vuelto hacia lo inteligible y eterno, permaneciendo en la quietud de un ahora inmutable, entonces, el tiempo como tal desaparecería. Sobre esto alega Plotino:

"¿Qué significaría "una cosa después de otra" si todo permanece en la unidad (̇̉v غ̇vi)? [...] ¿Cómo el Alma podría aplicarse a otra cosa que no fuese aquello en lo que

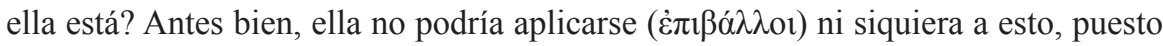
que debería estar primero alejada para poder aplicarse» $(12,12-15)$.

Porque tampoco existiría, en la quietud de lo invariable, la esfera celeste ( $\dot{\eta}$ $\sigma \varphi \alpha \tilde{\rho} \rho \alpha, 12,16)$ que no existe en sentido primario, ya que ella está en el tiempo y en él se mueve. Aunque la esfera celeste se detuviera, estando el Alma fuera de la

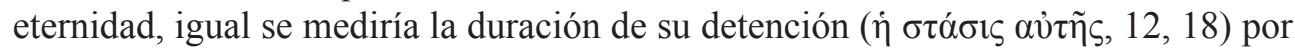
la actividad misma del Alma, lo que prueba la sujeción de la esfera celeste al tiempo $\mathrm{y}$, la de este, a la actividad del Alma. El tiempo, en consecuencia, es medido por el

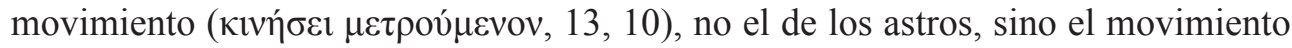

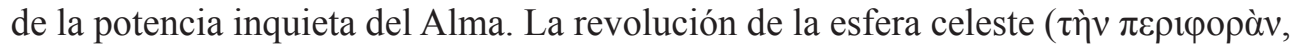
20-21) proporciona, sólo accidentalmente, una unidad mínima de medida de tiempo

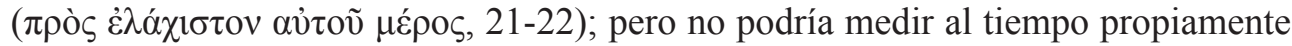
dicho dado que él ha nacido junto con el universo sensible y es a causa de tal actividad por la que este universo ha venido a la existencia. ${ }^{25}$

\section{Plan exegético y crítico sobre las opiniones precedentes en torno al tiempo}

Afirma Plotino que si los antiguos y bienaventurados varones no hubieran dicho nada acerca del tiempo, habría sido preciso, entonces, comenzar por la eternidad y lue-

\footnotetext{
${ }^{24}$ Cfr. García BazÁn, Francisco. Plotino y la mística de las tres hipóstasis. Buenos Aires: El Hilo de Ariadna, 2011, 245-249.

${ }^{25}$ Cfr. 12, 15-25; además, En. I, 5, 7, 14-20.
} 
go engarzar ese estudio con la exposición de las propias concepciones sobre el tiempo. Esto último, por cierto, intentando armonizar la opinión expuesta con la noción obtenida previamente en la mente. Sin embargo, el autor insiste en la necesidad de tener

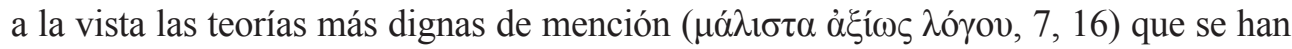
formulado acerca del tiempo y observar si la propia doctrina concuerda con alguna de ellas. En este sentido, Plotino divide en tres grupos las teorías que circulan a propósito del tiempo, toda vez que entre tales opiniones se supone la identificación del tiempo

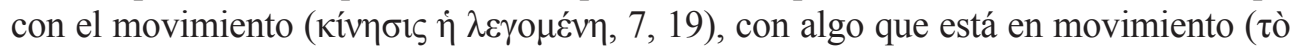

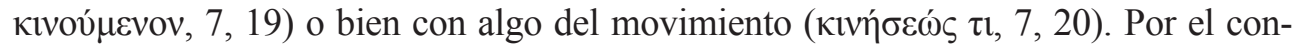
trario, decir que la noción de tiempo se identifica con el reposo ( algo que está en reposo ( 21) no se corresponde con la opinión más generalizada sobre el tiempo, toda vez que la percepción de este fenómeno está vinculada de suyo con el tema del cambio.

\section{1. El tiempo no se da sin movimiento}

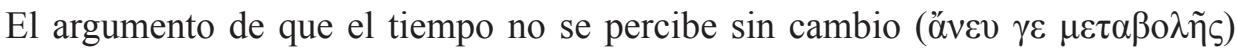
parece ser una opinión fundada, por cierto, en la tradición filosófica anterior al Neoplatónico. Es particularmente Aristóteles quien defiende este principio en la Física y demuestra con agudeza de análisis el modo intrínseco en que se vinculan movimiento y tiempo cuando se los pretende estudiar de manera científica, aunque sean de índole diferente. Como el presente trabajo procura ahondar en la crítica de Plotino dirigida contra Aristóteles a propósito del tiempo en cuanto atributo del movimiento, conviene recuperar las tesis del Estagirita acerca de la no identidad del tiempo con todo movimiento, puesto que ello permite introducirse en la noción de tiempo que entiende Aristóteles a fin de comprender, a partir de allí, lo que lo distancia de Plotino.

Dice el Estagirita que cuando nada cambia en el pensamiento, ${ }^{26}$ o cambia sin

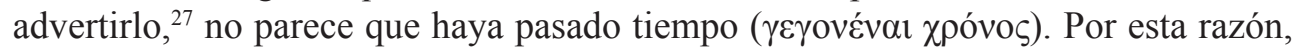
cuando no se determina cambio alguno, se dice que el alma parece permanecer en un

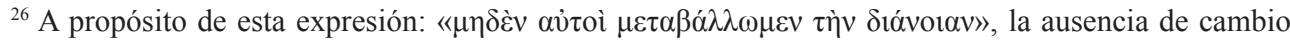
de pensamiento debe entenderse como una referencia a la ausencia de cambio interior psíquico (Cfr. Simplicio. In Aristotelis Physicorum Libros Commentaria (Libri I-IV). Ed. Diels, H.: Commentaria in Aristotelem Graeca 9. Berlin: Reimer, 1882, 708, 27-32) y no a la ausencia de representación de un cambio cualquiera (Cfr. Ibidem, 708, 34-709, 3).

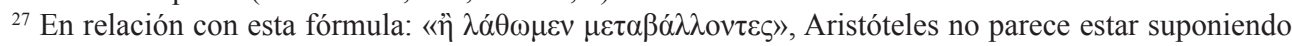
una ausencia efectiva del cambio, sea esta de índole exterior o interior, pues un estado semejante nunca se halla en la vida cotidiana. Estaría refiriéndose, más bien, a esas situaciones en las que la conciencia queda fijada a una representación vaga, durante la cual no se atiende a nada en particular, ni fuera ni dentro de uno mismo, y cuyo estado se intenta explicar por medio de frases como «por un momento, el tiempo parece haberse detenido» (Cfr. VIGO. 1995, 244).
} 


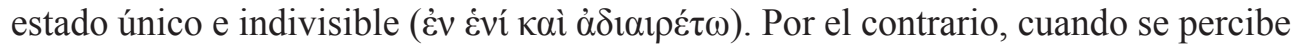
y determinan diferentes momentos o estados, se afirma que sí ha pasado tiempo. Sin movimiento ni cambio, entonces, no hay tiempo. A pesar de que este último no se identifica con el movimiento, tampoco se da sin él. ${ }^{28}$ Explica Aristóteles que percibimos ( $\alpha i \sigma \theta \alpha v o ́ \mu \varepsilon \theta \alpha)$ tanto el tiempo cuanto el movimiento de manera conjunta $(\check{\alpha} \mu \alpha)$; pues, basta con que se haya dado un movimiento en el alma para que parezca sin más haber pasado también tiempo. De manera inversa, siempre que parece haber pasado tiempo, se cree de igual modo que ha acontecido algún tipo de movimiento. En consecuencia, el Estagirita infiere que el tiempo habrá de ser o bien movimiento o bien algo en relación con el movimiento; como no es movimiento, será por tanto algo relacionado con él. ${ }^{29}$

Acerca de la interpretación de este pasaje, Vigo comenta que existe una vinculación esencial entre tiempo y movimiento, aun cuando ambos no se identifiquen entre sí. La argumentación aristotélica sobre este punto se lleva a cabo en dos etapas: (1) en primer lugar se manifiesta que el tiempo no se da sin movimiento o cambio; ${ }^{30}$ seguidamente, (2) el Estagirita agrega una prueba a propósito de ello. ${ }^{31}$ Teniendo en cuenta estos dos momentos, el movimiento es considerado, en el primero, como una condición necesaria de la presencia del tiempo; mientras que en el segundo, como una condición suficiente. ${ }^{32}$ Descartada, entonces, toda presunta identidad entre tiempo y movimiento, queda estipulada la condición del tiempo como algo del movimiento ( $\tau \tilde{\Upsilon} \varsigma \kappa ı v \varepsilon ́ \sigma \varepsilon \omega \varsigma \tau \iota) .{ }^{33}$ En este orden de ideas se observa, por tanto, que la relación entre movimiento y tiempo sostenida por Aristóteles es mucho más estrecha de lo que podría parecer de manera inmediata. Observa Vigo que uno de los puntos peculiarmente interesantes de la argumentación es el de que Aristóteles tiende a discutir el status del tiempo sobre la base de argumentos referidos a la experiencia concreta del cambio y la sucesión temporal, sólo que borrando la demarcación existente entre los ámbitos del ser y del conocer. ${ }^{34}$

En cuanto al primer argumento, el Estagirita asevera que no tenemos experiencia directa del tiempo con independencia de la experiencia que podamos tener del

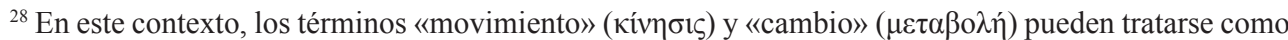
equivalentes. En 225a 20-b9 se establece una distinción entre ambos en el sentido de que $\mu \varepsilon \tau \alpha \beta$ o $\lambda \dot{n}$ es el término más amplio y puede aplicarse a todas la formas del cambio, incluso las del cambio sustancial;

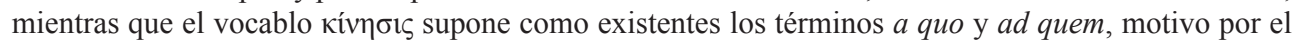
cual no es posible atribuirlo al cambio sustancial (Cfr. VIGO. 1995: 240-241).

${ }^{29}$ Cfr. Phys. 218b 21-219a 9.

${ }^{30}$ Cfr. Phys. 218b 21-219a 2.

${ }^{31}$ Cfr. Phys. 219a 2-8.

${ }^{32}$ Cfr. VIGO. 1995, 243-245.

${ }^{33}$ Cfr. Phys. 219a 8-10.

${ }^{34}$ Para el problema de la relación tiempo y alma en este tópico puede cfr. FestUGière, André-Jean. «Le temps et l'ame selon Aristote». En su: Études de Philosophie Grecque. Paris: Vrin, 1971, 197-220 (especialmente 210-220).
} 
movimiento o del cambio. En términos generales, la línea demostrativa seguida por Aristóteles es la siguiente, a saber, que la representación y percepción efectiva de lapsos temporales supone la discriminación entre, por lo menos, dos ahoras diferentes. Si bien esta discriminación presupone, a su vez, la presencia del movimiento o del cambio. Haciendo corresponder los ahoras con diferentes fases o momentos del cambio, es posible distinguir, por tanto, dos o más ahoras. De allí que la premisa fundamental de la investigación apunte a que la presencia de ahoras - o límites temporales - presuponga la del movimiento. ${ }^{35}$

Por lo que concierne al segundo apartado, dice Aristóteles que si se da movimiento, se da igualmente tiempo. Este argumento, con una conclusión de igual fuerza persuasiva que el anterior, no constituye una mera reiteración de las ideas ya expuestas y se justifica, además, por el lado de su contenido. El primer argumento ha mostrado que tanto el movimiento cuanto el cambio representan condiciones necesarias del tiempo. Si bien, lo que interesa delinear aquí es la relación que guarda el tiempo con el movimiento, toda vez que aquel ha sido determinado por el Estagirita como «algo del movimiento». Se añade, por tanto, un nuevo elemento de análisis para intentar abordar esta materia: el movimiento no sólo es condición necesaria, sino también condición suficiente del tiempo; pues basta que se constate cualquier movimiento para verificar a la vez la presencia de tiempo y, a la inversa, es suficiente con que se advierta que ha transcurrido cierto tiempo para suponer que se ha producido otro tanto de movimiento. Vigo manifiesta que el primer punto, referido al movimiento como condición necesaria del tiempo, se establece por recurso a la forma menos objetiva del cambio, representada por el cambio psíquico que se experimenta al interior de uno mismo. ${ }^{36}$ Con respecto al segundo punto, Aristóteles podría estar pensando en ciertas vivencias corrientes de la vida diaria, tales como el suponer que una persona habría sufrido cambios en su aspecto exterior a causa del paso del tiempo. ${ }^{37}$

\section{5. ¿Cabe al tiempo ser número o medida del movimiento?}

\section{1. El tiempo no es la medida de todo movimiento $(9,1-12)$}

Ambas expresiones, vale decir, la de «número» o bien «medida del movimiento» se hallan consignadas en Aristóteles, ${ }^{38}$ aunque Plotino aduce que es preferible hablar de «medida» en lugar de «número» toda vez que el movimiento es continuo

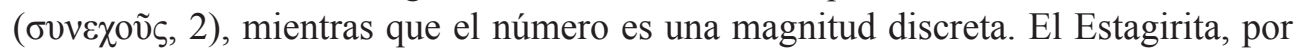

\footnotetext{
${ }^{35}$ Cfr. Phys. 219a 22-b 2.

${ }^{36}$ Cfr. Phys. 219a 3-6.

${ }^{37}$ Acerca de la noción de corruptio a causa del paso del tiempo cfr. Phys. 222b 16-26.

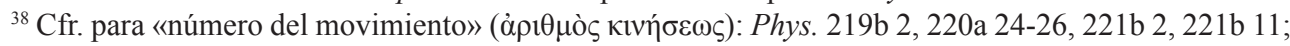

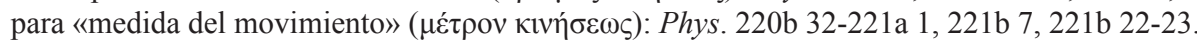


su parte, admite de hecho que el tiempo es número o medida de un movimiento continuo. ${ }^{39} \mathrm{Si}$ bien observa que el tiempo mide el movimiento en virtud de determinar (ópíбal) un cierto movimiento que sirve de unidad para medir el movimiento total ( por la determinación de una magnitud ( $\tau \mu \mu \varepsilon_{\gamma \varepsilon} \theta$ os) empleada para medir la longitud

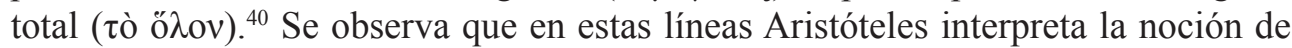
«estar en el tiempo» en términos de «estar medido por el tiempo». Con respecto al significado general de este «estar en el tiempo», se parte del caso particular del movimiento. Si el tiempo es medida del movimiento, al decir que el movimiento está en él, se está parafraseando entonces lo propio del tiempo, esto es, se está mostrando que «estar en el tiempo» no es sino «estar siendo medido por el tiempo». ${ }^{41}$ Esta medida se extiende incluso hasta el hecho del estar en movimiento o del moverse en

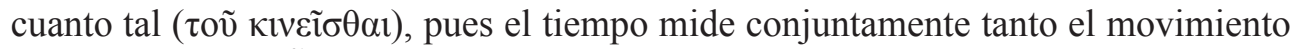
cuanto el ser ( $\tau$ ò Eĩval) de él. ${ }^{42}$ A propósito de esta misma particularidad, Simplicio advierte la coincidencia entre la unidad de medida del objeto y de su ser. Ambas son unidades de tiempo puesto que, en el caso del movimiento, su ser mismo consiste en

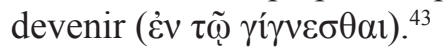

A pesar de que Aristóteles piensa el tiempo como número de todo movimiento en cuanto movimiento, ${ }^{44}$ Plotino se muestra remiso ante la idea de que el tiempo sea de tal índole. «Porque - en palabras del mismo Neoplatónico - ¿qué tiempo puede nu-

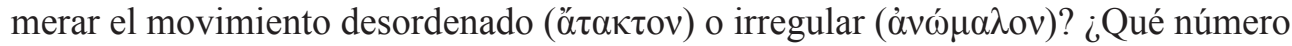

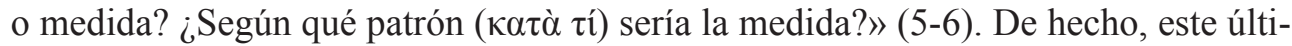
mo plantea la cuestión de que si se midiera conforme con el mismo patrón ( $\tau \tilde{\omega}$ av่ $\tau \tilde{\omega}$, 7) uno y otro movimiento ( $\dot{\varepsilon} \kappa \alpha \tau \dot{\varepsilon} \rho \alpha \nu, 7)$ y todo movimiento en general (ö $\lambda \omega \varsigma \pi \tilde{\alpha} \sigma \alpha \nu$, 7), rápido $(\tau \alpha \chi \varepsilon \tilde{i} \alpha \nu, 7)$ o lento $(\beta \rho \alpha \delta \varepsilon \tilde{\alpha} \alpha v, 7)$, tal como propugnaba Aristóteles ${ }^{45} \mathrm{el}$ tiempo mismo se asemejaría, por tanto, a una magnitud - una decena v. gr. - que me-

\footnotetext{
${ }^{39}$ Cfr. Phys. 220a 24-26: «Es manifiesto, en suma, que el tiempo es número del movimiento según

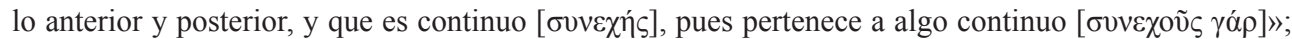

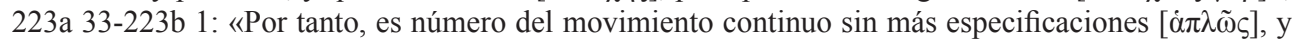

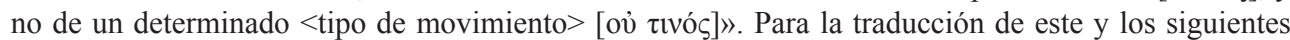
pasajes sigo la versión de VIGo. Buenos Aires: Editorial Biblos, 1995; aunque también he consultado la versión de Aristóteles. Física. Intr., trad. y notas de Rodríguez de Echandía, G. Madrid: Gredos, 1982 (Reimpr. 2007).

${ }^{40}$ Cfr. Phys. 220b 32-221a 4.

${ }^{41}$ Cfr. Phys. 221a 4-7.

${ }^{42}$ Cfr. Vigo. 1995, 265-266, ad 220b 32-221a 9.

${ }^{43}$ Cfr. Simplicio. 1882, 735, 34-736, 22; Ross. 1936, 605, ad 221a 1.

${ }^{44}$ Cfr. Phys. 223a 32-223b 1.

${ }^{45}$ Cfr. Phys. 223b 6-8: «Así también a los movimientos que se completan simultáneamente [ $\tau \tilde{\omega} v$ ö $\mu \alpha$

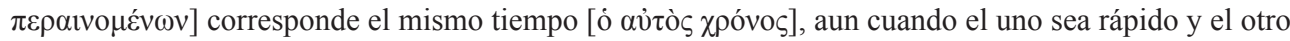

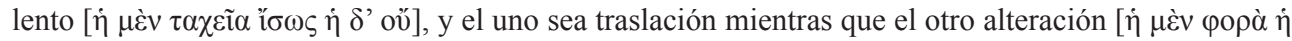
$\left.\delta^{\prime} \dot{\alpha} \lambda \lambda \operatorname{oí}^{\prime} \omega \sigma 1 \varsigma\right] »$.
} 
diría de igual forma entidades diversas: caballos tanto como bueyes o bien líquidos y

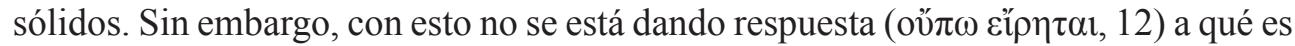

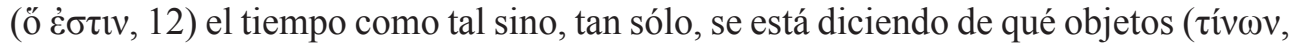
11) es medida o número.

\section{2. El tiempo no es ni un número abstracto ni magnitud continua $(9,12-24)$}

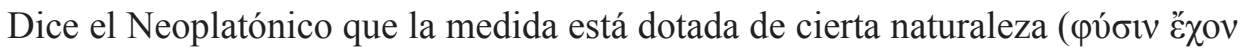

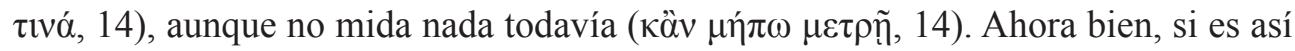
como tiene que ser, también el tiempo en cuanto medida, si en sí mismo es una medi-

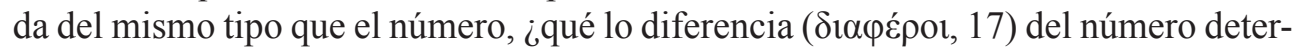
minado que corresponde a cualquier otra cantidad o cifra aritmética? Entretanto, si es una magnitud continua ( $\sigma v v \varepsilon \chi \grave{\varepsilon} \varsigma, 17-18$ ), será medida por ser de cierta dimensión

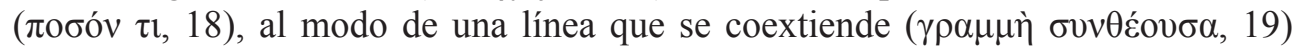
junto con el movimiento. Sin embargo, si el tiempo es como esa línea co-extensible con el movimiento, ¿cómo medirá ( $\mu \varepsilon \tau \rho \eta ́ \sigma \varepsilon 1,20)$, entonces, aquello con lo cual se

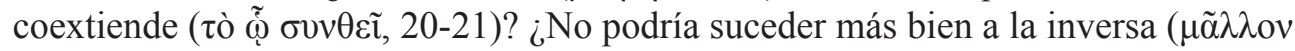
[...] Өá $\varepsilon \varepsilon \rho o v, 21)$ - expresa Plotino - que el movimiento mida al tiempo? Porque si ambos son conjuntamente extensibles, entonces, ¿cuál es el patrón para decidir qué es lo mensurado y qué, lo medidor? Además, si la línea del tiempo es co-extensible con el movimiento, sería mucho más verosímil superponerla no a todo movimiento sino tan sólo a aquel con el que se coextiende. Pero también este último no debe ser cualquier tipo de movimiento sino uno de carácter continuo, porque si no la línea que

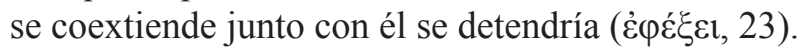

\section{3. El tiempo no es ni movimiento mensurado ni sujeto mensurador (9, 24-84)}

En su doctrina acerca del tiempo, Aristóteles puntualiza que el tiempo es número pero no en el sentido de número como un instrumento del que nos servimos

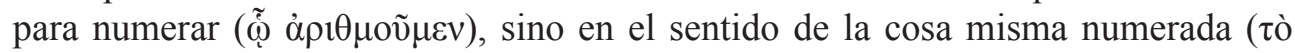

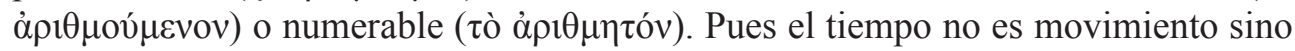
en cuanto el movimiento comporta ( $ع \chi \varepsilon \varepsilon)$ número. Por su misma realidad fáctica, el tiempo se identifica con el movimiento; en cuanto a su esencia, empero, tiempo es el movimiento en cuanto numerado o numerable según lo anterior y posterior. A causa del mutuo determinarse (ópí $\varepsilon \sigma \theta \alpha$ l) de uno por otro ( $\left.\dot{v} \pi^{\prime} \dot{\alpha} \lambda \lambda \dot{\eta} \lambda \omega v\right)$, el tiempo determina el movimiento en tanto es su número, mientras que el movimiento al tiempo porque se predica mucho o poco tiempo en razón del movimiento transcurrido. ${ }^{46}$

Plotino afirma que lo mensurador, en este caso el tiempo, no debe tomarse como algo extrínseco $(\check{\varepsilon} \xi \omega \theta \varepsilon v, 24)$ y separado ( $\chi \omega$ pí $\left._{\text {, }} 24\right)$ del movimiento mensurado. Sin

$\overline{{ }^{46} \text { Cfr. Phys. 219b 2-9 }}, 10-12 ; 220$ b 8-9, 14-20. 
embargo, se interroga nuevamente de qué índole será eso mismo que mide. ${ }^{47}$ Pues si el movimiento ha resultado mensurado ( $\mu \varepsilon \mu \varepsilon \tau \rho \eta \mu \varepsilon ́ v \eta, 26)$, tiene que haberlo men-

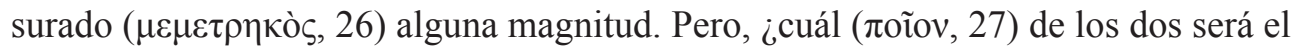
tiempo: la magnitud mensuradora ( $\mu \varepsilon \tau \rho \tilde{\eta} \sigma \alpha v, 28)$ o el movimiento mensurado? Los numerosos y agudos interrogantes que Plotino formula, muestran que el argumento continúa brindando aporías y no soluciones satisfactorias a la cuestión del tiempo.

Continúa el Neoplatónico: según el planteo al que se ha arribado, tiempo será o el

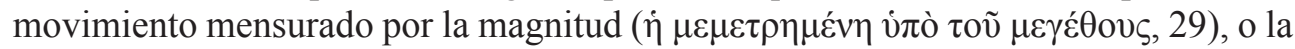
magnitud mensuradora ( $\tau$ ò $\mu \varepsilon ́ \gamma \varepsilon \theta$ o $\tau$ ò $\mu \varepsilon \tau \rho \tilde{\eta} \sigma \alpha v, 30$ ) o bien el sujeto que se sirvió de tal magnitud para medir la cantidad de movimiento ( En cualquiera de los tres casos precedentes, hay que partir de la hipótesis de que se está refiriendo a un movimiento regular (ó $\mu \alpha \lambda \eta े v, 33)$. Porque si no hay regularidad

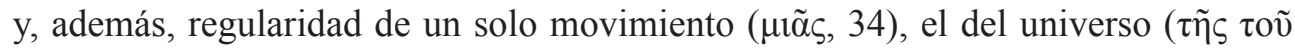
ő $\lambda$ ov, 34), resulta por ello más problemática $(\dot{\alpha} \pi \circ \rho \omega ́ \tau \varepsilon \rho o v, 34)$ la posición de que el tiempo sea medida del movimiento.

Se ha dado por sentado que el movimiento deba tener una medida diferente ( $\alpha \lambda \lambda \lambda_{0}$,

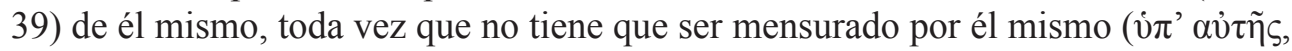

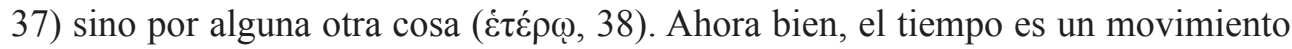

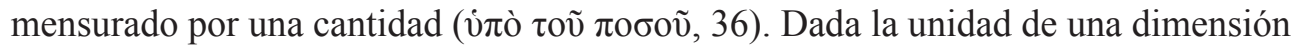
determinada por la que se mida la cantidad de movimiento, se sigue por necesidad

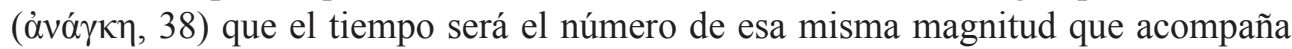

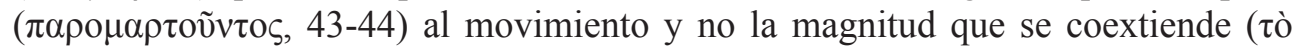

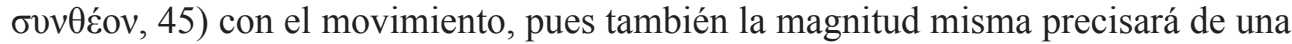

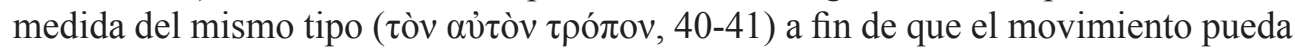
ser medido $(\mu \varepsilon \tau \rho \eta \theta \tilde{\eta}, 42)$.

Ahora bien, dado que se habla del tiempo como un número, ¿de qué otro número se trata más que del aritmético (ó $\mu$ ov $\alpha \delta$ ı́ó, 45)? Surge inevitablemente el problema de cómo (ö $\pi \omega \varsigma, 46)$ este número habría de efectuar la medición correspondiente

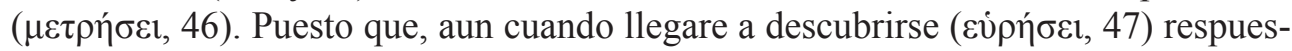
tas plausibles a este cómo, el objeto de su medición será siempre no un tiempo

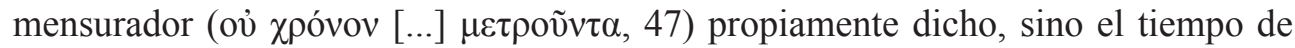
una dimensión determinada ( al tiempo mismo como tal, sino al tiempo de una dimensión determinada. En consecuencia, esta última determinación no es lo mismo que el tiempo, ya que una cosa es decir el tiempo por sí mismo ( $\tau \alpha$ ì̀ò, 48 ) y otra bien distinta decir el tiempo de

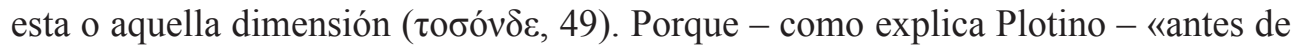
decir: "de una dimensión determinada", hay que decir qué es aquello que es de una dimensión determinada». ${ }^{48}$

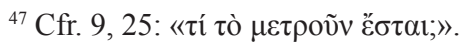

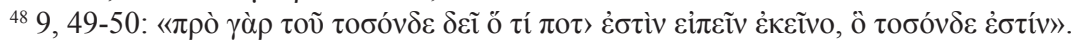


Bien podría el tiempo ser el número que mide el movimiento desde fuera del movimiento mismo, como en el caso de la decena que se emplea para medir caballos o bueyes. De una forma u otra, Plotino insiste en el hecho de que tampoco por medio

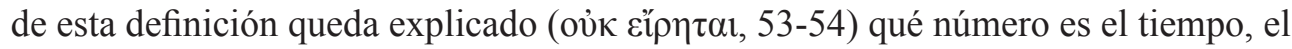
cual es lo que es (ö $\pi \varepsilon \rho \dot{\varepsilon} \sigma \tau i ́ v, 54)$, es decir, es número antes de aplicarse a la medición de cualquier objeto ( $\pi \rho o ̀ ~ \tau o \tilde{~} \mu \varepsilon \tau \rho \varepsilon \tilde{v}, 54)$. Se da por sentado que es una determinada cantidad en función del objeto al cual esa cantidad mide, en este caso, el movimiento; pero no se dice qué es esa magnitud.

Si se dijera, por cierto, que se trata de esta misma magnitud co-extensible con el movimiento, que corre de manera paralela a él $(\pi \alpha \rho \alpha \theta \varepsilon ́ \omega v, 56)$, no está claro todavía qué número es el tiempo que mide según lo anterior y posterior. En todo caso - declara Plotino - puesto que mide según lo anterior y posterior, sea por medio de un

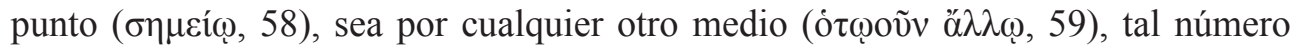

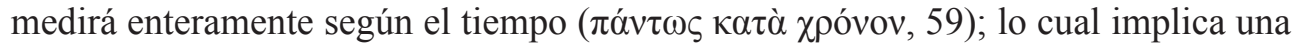
contradicción, porque el tiempo será, pues, este número que mide el movimiento me-

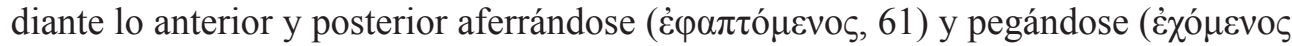

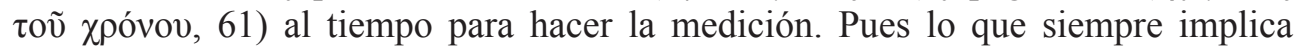

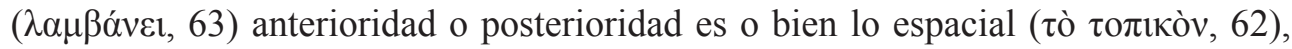
como el comienzo de un estadio, o bien forzosamente lo temporal (

Manifiesta Plotino que tanto lo anterior cuanto lo posterior son tiempos: uno fina-

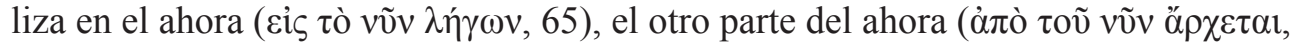
65). Sin embargo, en la definición aristotélica del tiempo se aprecia que lo anterior y lo posterior no son períodos de tiempo, sino límites de períodos de tiempo. ${ }^{49} \mathrm{La}$ conclusión a la que llega el razonamiento precedente es que el tiempo es algo distinto (i่vนıvoṽv, 67) del número que mide según lo anterior y posterior no sólo un

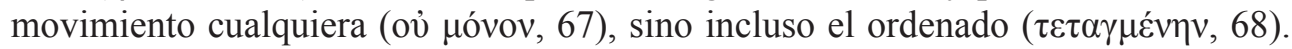
Insiste en la cuestión de por qué motivo el tiempo tiene que surgir al originarse ( $\pi \rho о \sigma \gamma \varepsilon \gamma \varepsilon v \eta \mu \varepsilon ́ v o v, 68-69)$ el número, sea este de índole mensuradora o mensurada. Por qué no, en cambio, ha de haber tiempo aunque haya movimiento y aunque esté,

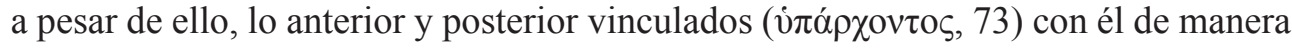
indisoluble. Es como si se dijese que la magnitud no es de la dimensión de que es ( $\mu$ ì

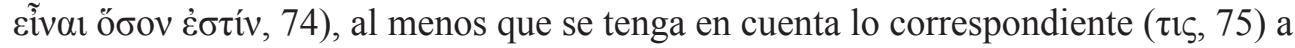

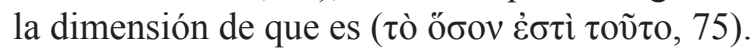

Por último, arguye Plotino que dícese del tiempo que es infinito (A $A \varepsilon i ́ p o v, 75)$. ¿Cómo puede, en efecto, serle inherente la categoría de número si es infinito? Si

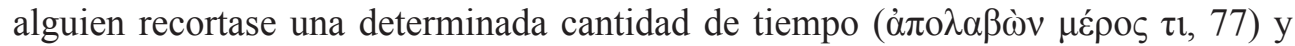
la midiera, con ello tampoco se diría qué es el tiempo pues antes de la medición del

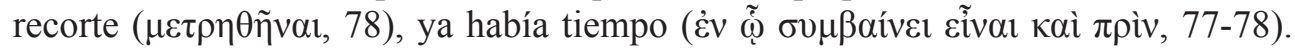
Y por qué no, entonces, podría haber tiempo antes de que existiese el alma singular

\footnotetext{
${ }^{49}$ Cfr. Phys. 219a 22-219b 1.
} 


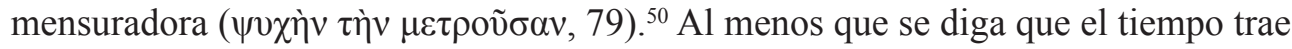
del Alma su origen, ${ }^{51}$ si se piensa en función del acto de medir propiamente dicho, tal explicación no sería precisa en absoluto porque el tiempo es de la constitución que

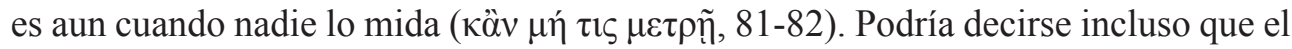
sujeto que se vale de la magnitud para medir es el alma, pero esto tampoco contribu-

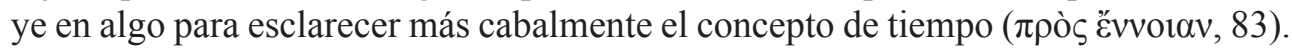

\section{A modo de conclusión: Aristóteles confunde el metro con lo medido (13, 1-40)}

A los efectos de dar término a esta exposición de la valoración crítica que el Neoplatónico realiza sobre la comprensión aristotélica del tiempo, conviene cerrar el presente trabajo haciendo las siguientes concisiones:

(1) Plotino concluye su indagación acerca del tiempo aclarando que la rotación celeste manifiesta el tiempo en el que ella misma está y se mueve, pero el tiempo como tal no debe ya tener algo donde estar. Siendo anterior $(\pi \rho \tilde{\omega} \tau o v, 2)$ a todas las cosas que regular y ordenadamente se encuentran en estado tanto de reposo cuanto de cambio no es, sin embargo, originado por alguna de aquellas entidades, sino por el principio del movimiento del Alma hacia el mundo sensible. ${ }^{52}$ Como es más asequible para el conocimiento saber cuánto ha durado una cosa en movimiento ( $\tau$ ò

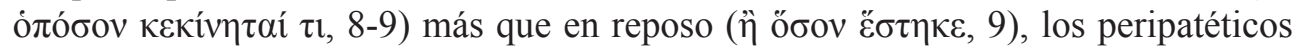
- observa Plotino - fueron inducidos por esta causa a definir el tiempo como medida del movimiento, en lugar de describirlo como medido ( $\mu \varepsilon \tau \rho o v ́ \mu \varepsilon v o v, 10)$ por el movimiento y añadir, luego, de qué naturaleza u orden es eso mismo que es medido. Se impugna, en este sentido, la concepción aristotélica del tiempo porque sólo se limita a mencionar, y de modo trastocado, algo que surge accidentalmente en una parte del tiempo. Pese a que los peripatéticos hablaban de medida en el sentido de «lo medido», el Neoplatónico observa que la causa principal donde radica su falta de claridad conceptual se debe a que ellos no aclararon qué es ( $\tau i ́$ ôv, 16), en definitiva, el tiempo, tanto si mide como si es medido.

(2) Desde otro ángulo de la consideración, el Neoplatónico ha precisado que el Alma engendra el tiempo, mientras que el universo está en el tiempo y en él se mueve. Se colige, entonces, que el Alma envuelve al mundo sensible y lo pone en movimiento, puesto que si bien el movimiento del todo cósmico permite medir el

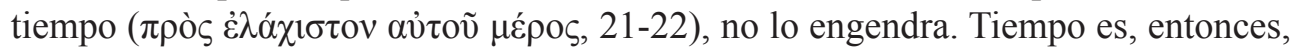
la extensión de la vida misma del Alma, que cumple una actividad incesante y que

\footnotetext{
${ }^{50}$ En Phys. 223 a 21-29, Aristóteles plantea la controversia de si habría tiempo sin alma pues «ninguna otra cosa es por naturaleza capaz de numerar ( $\pi \dot{\varepsilon} \varphi v \kappa \varepsilon v \dot{\alpha} \rho \imath \theta \mu \varepsilon i v)$ sino el alma (ì $\psi v \chi \eta ́)$ y su intelecto ( $\psi v \chi \tilde{\eta} \varsigma$ voũ $\varsigma) »$. En relación con esta aporía cfr. el estudio desarrollado por FestUGIÈRE, A.-J. «Le temps et l'ame selon Aristote». op. cit., 197-209.

${ }^{51} \mathrm{Sc}$. del Alma en cuanto hipóstasis tercera y no del alma singular que habita en el mundo sensible.

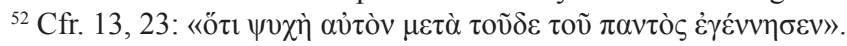


procede a través de cambios uniformes y semejantes unos con otros. Esta sucesión de cambios transcurre en silencio gracias a la continuidad de la vida anímica que jamás terminará, toda vez que se trata del acto de una Hipóstasis que existe eternamente. ${ }^{53}$ Se trata de un movimiento espontáneo y que, de la misma forma que engendra sus propios actos, engendra también la sucesión consecutiva, es decir, engendra tales actos a la vez que engendra la transición de uno a otro. ${ }^{54}$

(3) Para finalizar y únicamente teniendo a la vista el estudio que ha sido realizado, es dable señalar que, de entre los puntos conclusivos que podría ofrecer el presente trabajo, se halla el hecho de haber mostrado el desarrollo medular de una discusión dialéctica frente a una temática en común. En este sentido, se ha intentado recuperar la posición filosófica de Plotino con respecto al tiempo, junto con sus propias argumentaciones teóricas, a fin de encuadrarla en el marco de su propio núcleo sistemático de ideas. Desde allí se ha dilucidado la crítica de Plotino a las categorías empleadas por Aristóteles en su definición del tiempo. En la medida en que el análisis seguido a lo largo de estas páginas estriba principalmente en comparar o presentar posiciones filosóficas, que pueden ser muy divergentes aun cuando discutan en torno a un mismo tópico, tal examen puede ser orientador para el lector que desee incursionar o introducirse tanto en el tema sobre el que se está discutiendo - en este caso, el tiempo - cuanto en el ejercicio dialéctico que nutre esa misma confrontación.

\footnotetext{
${ }^{53}$ Cfr. $12,1-8$.

${ }^{54}$ Acerca de la relación entre el movimiento y el alma en su marcha ascendente hacia la comunión con el Uno cfr. En. VI 9, 8 y el comentario a este pasaje realizado por ZuBIRIA, Martin. El amor sapientiae ante la diferencia absoluta (Plotino, VI 9). Mendoza: SS\&CC Ediciones, 2012, 97-108.
} 


\section{Bibliografía}

Albizu, Edgardo. «Esquemas de tiempo». Letras, 48, 84-85, 1976, 16-40.

Armstrong, Arthur Hilary. The Architecture of the Intelligible Universe in the Philosophy of Plotinus, Cambridge: University Press, 1940.

Aristóteles. Física. Intr., trad. y notas de Rodríguez de Echandía, G. Madrid: Gredos, 1982 (Reimpr. 2007).

Aristóteles. Física. Libros III-IV. Trad., intr. y com. de Vigo, A. Buenos Aires: Editorial Biblos, 1995.

Aristóteles Metafisica de. Ed. trilingüe por García Yebra, V. Madrid: Gredos, 1998.

von Arnim, Hans. Stoicorum Veterum Fragmenta. Vol. II. Stuttgart: Teubner, 1979 $\left(1903^{1}\right)$.

Beierwaltes, Werner. Über Ewigkeit und Zeit (Enn. III 7). Texto gr., trad. al. y com. Frankfurt am Main: Klosterman, 1967 (1981³).

Boethius, S. De Consolatione Philosophiae. PL 63, 579 D-870 A.

Festugière, André-Jean. «Le temps et l'ame selon Aristote». En su: Études de Philosophie Grecque. Paris: Vrin, 1971, pp. 197-220.

García Bazán, Francisco. Plotino y la mística de las tres hipóstasis. Buenos Aires: El Hilo de Ariadna, 2011.

—_ «El tiempo y la historia en el Neoplatonismo y San Agustín». Revista del Museo Mitre, 10, 1997, 73-84.

Guitton, Jean. Le temps et l'éternité chez Plotin et Saint Augustin. Paris: Boivin et $\mathrm{C}^{\text {ie }}$. Éditeurs, 1933.

Liddell, H. G. \& Scott, R. (eds.). Greek-English Lexicon. Oxford: University Press, $1966^{9}$.

Martin De Blassi, Fernando. «Algunas notas acerca de la comprensión plotiniana del tiempo: un sendero medieval en relación con el binomio permanencia-devenir». En Díez, Ricardo (Comp.). Senderos medievales, pasos contemporáneos. IX Jornadas de Filosofía Medieval. Buenos Aires: Academia Nacional de Ciencias de Buenas Aires-Conicet, 2014 (Formato CD).

Parmenides. «Fragmenta». En: Die Fragmente der Vorsokratiker. Ed. Diels, H. \& Kranz, W. Vol. 1. Berlin: Weidmann, $1951^{6}$ (repr. Dublin/Zurich: 1966).

Pigler, Agnès. Ennéade III, 7 [45]: De l'éternité et du temps. Plotin. Paris: Ellipses, 1999. 
Platonis opera (Timaeus). Ed. Burnet, J. Vol. 4. Oxford: Clarendon Press, 1902 (repr. 1968).

Platón. Diálogos VI (Filebo, Timeo, Critias, Cartas). Intr., trad. y notas de Durán, Ma. A.; Lisi, F.; Zaragoza, J.; y Gómez Cardó, P. Madrid: Gredos, 1982 (Reimpr. 2007).

Plotini opera. Henry, P. et Schwyzer, H.-R. 3 vols. Paris-Bruselas-Leiden: Brill, 1951-1973 (editio maior).

—, t. I-II (= Vita Plotini y Enn. I-IV), Oxford: Clarendon Press, 1964-1977 (editio minor).

Plotino. Enéadas. Textos esenciales. Intr., trad. y notas de Santa Cruz, Ma. I.-Crespo, Ma. I. Buenos Aires: Colihue, 2007.

Porfirio. Vida de Plotino-Plotino. Enéadas I-II, III-IV, V-VI. Intr., trad. y notas de Igal Alfaro, J. Madrid: Gredos, 1982-1998.

Ross, William David. Aristotle's Physics. Revised text, intr. and comm. Oxford: Clarendon Press, 1936.

Simplicio. In Aristotelis Physicorum Libros Commentaria (Libri I-IV). Ed. Diels, H.: Commentaria in Aristotelem Graeca 9. Berlin: Reimer, 1882.

Zubiria, Martín. El amor sapientiae ante la diferencia absoluta (Plotino, VI 9). Mendoza: SS\&CC Ediciones, 2012.

Fernando G. Martin De Blassi

Centro de Estudios Filosóficos Medievales (CEFIM)-

Universidad Nacional de Cuyo-CONICET (Argentina)

martindeblassi@hotmail.com 